\title{
Structure of the FindFish Knowledge Transfer Platform
}

\author{
Lidia Dzierzbicka-Głowacka, Artur Nowicki, Maciej Janecki, Beata Szymczycha, Piotr \\ Piotrowski, Piotr Pieckiel, Grzegorz Łukasiewicz
}

Received - 13 March 2018/Accepted - 20 September 2018. Published online: 30 September 2018; $\odot$ Inland Fisheries Institute in Olsztyn, Poland Citation: Dzierzbicka-Głowacka L., Nowicki A., Janecki M., Szymczycha B., Piotrowski P., Pieckiel P., Łukasiewicz G. 2018 - Structure of the FindFish Knowledge Transfer Platform - Fish. Aquat. Life 26: 193-197.

\begin{abstract}
As consumer awareness increases in Poland, fish consumption is on an upward trend. While new technologies permit meeting increasing demand, they significantly increase the pressure on fish supplies. As a result, many fish stocks are over-exploited, which threatens marine ecosystems. Declining fisheries, increasing fishing operating costs, and the necessity of making longer fishing expeditions at greater distances that often end with catches of fewer or less valuable fish mean that in some fisheries sectors are currently running at the margins of profit or at a loss. At the same time, the European Union's fisheries policy aims to create more selective and sustainable fisheries, to implement limitations through fishing quotas, and to ban the recognition of discards. The aim is to ensure that individual fish species are protected while providing the European Union with stable, secure supplies of fresh fish. The FindFish Knowledge Transfer Platform project was launched to provide solutions for challenges facing commercial fisheries. Its purpose is to provide fishers with a knowledge transfer platform and a numerical forecasting system for the marine environment of
\end{abstract}

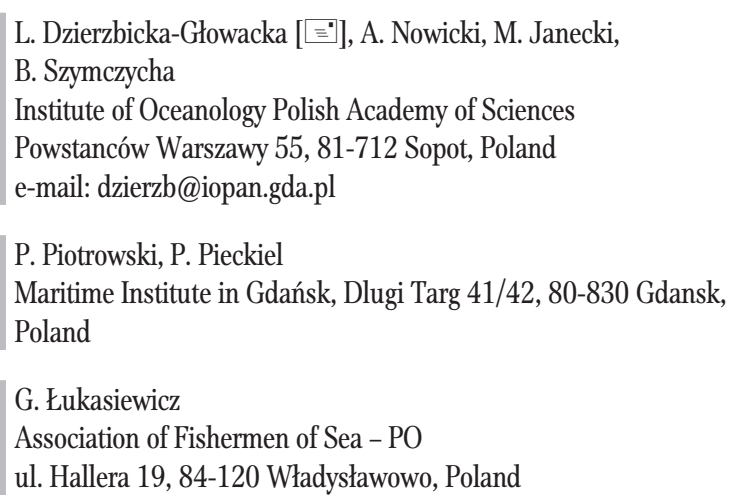

the Gulf of Gdansk. By combining in-situ research, environmental data, fish catch data, and numerical calculations, this tool will improve the accuracy of targeted fishing while reducing by-catch. The system will provide more reliable data on fish stocks and facilitate more efficient resource management.

Keywords: Baltic Sea, fisheries forecasting, knowledge transfer, numerical models

Each fish shoal is part of complex marine ecosystem, the functioning of which is hard to predict. Many studies focus on understanding fish behaviour and attempt to model the spatial and temporal distribution of fish using a number of approaches (Rushton et al. 2004, Smith et al. 2007, Planqué et al. 2011). Key factors impacting fish stocks in the marine environment include rapid technological progress, the use of state-of-the-art equipment, wide ranging marine pollution (Sindermann 1980), the development of coastal cities, global warming (MacKenzie and Köster 2004, MacKenzie et al. 2007, Hiddink and Coleby 2011), and proper fisheries management (Thøgersen et al. 2015). The scale and pace of changes in the marine environment make successful fishing increasingly difficult. Costs associated with commercial fishing are steadily growing, and one of the ways to reduce them is to use the technology to locate and estimate fish stock sizes, numbers, and 
species. The variety of equipment available permits choosing different fishing vessels for each type of fishing.

The last two decades have seen tremendous progress in the development of the sonar techniques used in fisheries. It is estimated that the use of modern sonars brings measurable economic savings by reducing time and fuel consumption by about $25 \%$ (European Commission 2009). However, this is still an expensive undertaking, and presently it often remains difficult to implement. Similarly, in situ and satellite measurements are expensive and pose significant technical difficulties, which makes using them challenging. Nevertheless, projects aimed at providing these services have been conducted, e.g., FishSat by the European Space Agency or DigitalGlobe Marine Services.

Another challenge facing the industry is legislation that restricts the quantities of fish harvested by the fisheries and establishes quality standards to protect fish populations and their habitats and ecosystems. These standards are a response to declining fish stocks worldwide. Emphasis is placed on designing better equipment and technologies that facilitate more selective fishing with regard to both fish sizes and species that can lead to sustainable fishing (Walsh et al. 2002).

In this study, we introduce a new systemic approach referred to as FindFish that is being developed within the research project entitled the FindFish Knowledge Transfer Platform. The main focus of this system is to provide complex and accurate information for fishers and fisheries. The numerical method proposed in the paper aims to assist forecasting the places of occurrence of the largest fish stocks and to identify the prevailing conditions in particular areas of the Gulf of Gdansk. The introduction of a computer modeling system based on the highest degree of correlation between meteorological, hydrodynamic, and biochemical conditions in the studied area with the occurrence of individual fish species based on actual catch data will have a substantial impact on the profitability of the fisheries. However, to design a model that is accurate enough is a very difficult task. Often this kind of model fails to work properly (Schnute and Richards 2011) because of a lack of information, insufficient data, or incorrect assumptions.

The FindFish project addresses problems that were identified as contributing to the declining profitability of commercial fisheries and increased fishing times and emissions of pollutants into the environment. Numerical modeling will allow fishers to make the most economical use of available catch limits. An added value of the project will be to improve maritime safety and working conditions. Catching the same quantity of fish during shorter fishing trips will relieve vessel crews and improve safety. Fuel consumption will also decrease, leading to further savings and less environmental pollution. Decisions taken by captains determine whether vessels return safely to port in time and whether catches are abundant; these decisions must be made optimally so that profits are as great as possible and losses are minimized. Access to the FindFish Platform will facilitate greater accuracy in decision making.

The FindFish Knowledge Transfer Platform (Fig. 1) will be based on in situ research, environmental data, quantitative and qualitative data on fisheries, and the numerical modeling of the hydrodynamic, physicochemical, and biological parameters of the Gulf of Gdansk. Using a model working in operational mode, the system created based on various data sources will provide current forecasts on hydrodynamic and physicochemical conditions and the marine biological environment of the Gulf of Gdansk, as well as the probable locations of particular commercial fish species. The system will be created based on prepared historical and current in situ data collected during fishing expeditions that are transmitted to the system by fishers, numerical data provided by scientists, and satellite data.

After its final implementation, the system will provide maps based on numerical simulations that indicate where, when, and under what environmental conditions the largest fish shoals of particular species can be found. The well-designed and implemented platform, which is the substantive basis of the system and is updated on a regular basis 


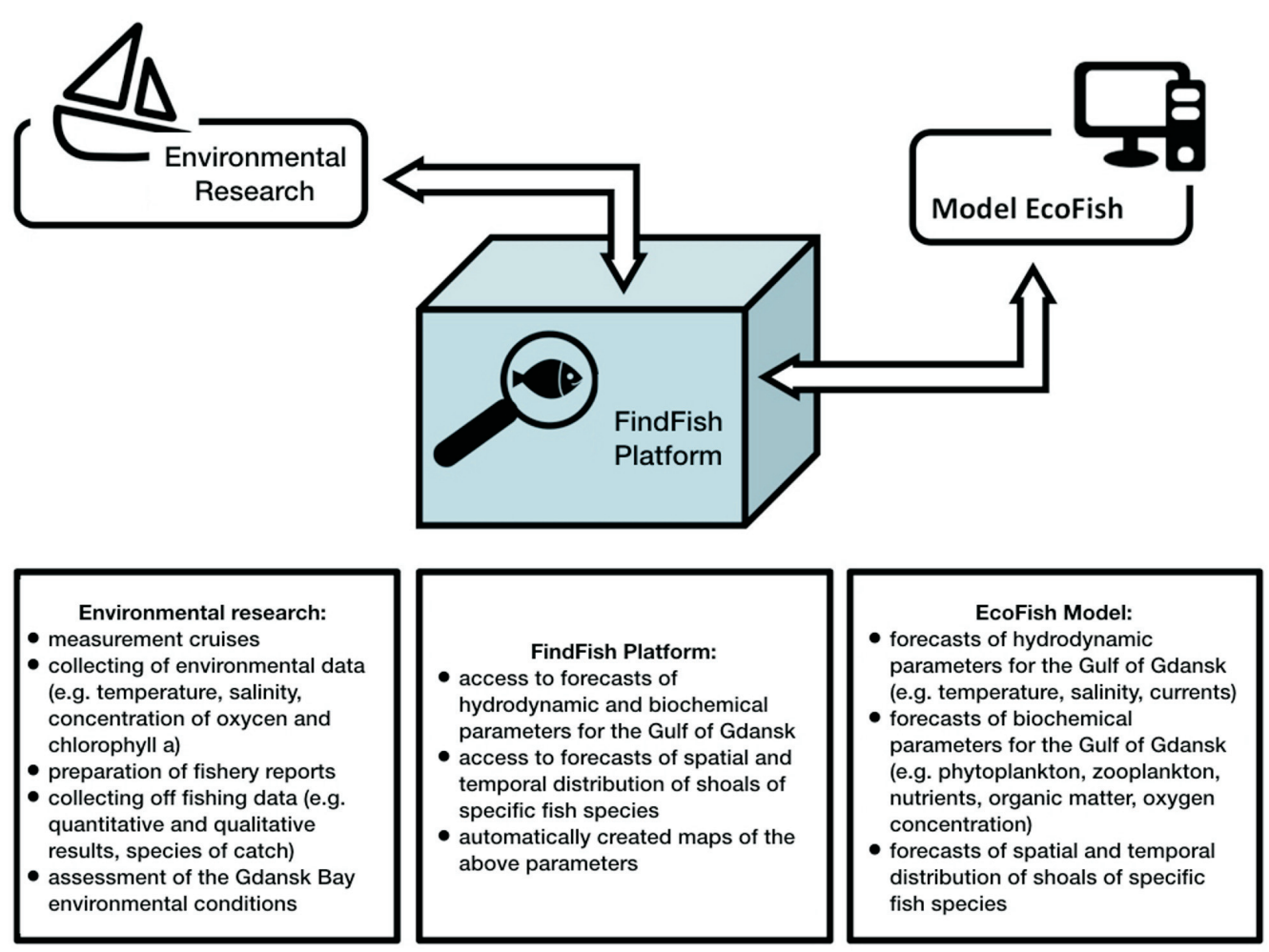

Figure 1. FindFish Knowledge Transfer Platform schema.

with new data obtained from the numerical model with satellite and environmental data assimilation modules, will provide the possibility of predicting the conditions of the marine environment and potential locations of fish shoals that are targeted by the fisheries. Additionally, the platform will allow for the creation of a historical database that can be used for further research and to broaden knowledge of the topics investigated in this project and potentially in others.

Such a large-scale undertaking requires the cooperation of fishers, scientists, and specialists from various fields. The research is divided into six main stages. During each stage particular tasks will be accomplished building up to the completion of the system.

The first stage is the assessment of the state of the environment of the Gulf of Gdansk. This means the current ecological and chemical state of the Gulf of Gdansk area will be analyzed from the point of view of the ichthyofauna based on existing and new data.
The analysis will permit identifying the environmental preferences of selected commercial fish species caught in the Gulf of Gdansk.

Stage two is fishing expeditions, during which measurements will be taken using specialized probes. The aim is to gather environmental data, which, along with notes from fishing logs and other data provided by vessel captains, such as meteorological data, fishing results, observations, and comments, will be used in the EcoFish three-dimensional forecasting model for the Gulf of Gdansk. Some fishing vessels will be equipped with state-of-the-art net echosounders and NMEA net sonars. With time calibrations, it will be possible to integrate measurements of the quantities of fish entering active fishing gear (quantitative measurements with a graphical method at the inlet) with the internal clocks of the probes and to show the exact relationship between fish abundance and water parameters measured.

The EcoFish model will be developed during the third stage of the project. The design and 
development of the three-dimensional EcoFish model for the Gulf of Gdansk consisting of three main modules-hydrodynamic, biochemical, and fish-for the FindFish system will be conducted during this stage. The model will enable monitoring the marine environment of the Gulf of Gdansk and permit tracking and predicting changes and determining the potential occurrence of specific fish species caught commercially in the studied area. Additionally, the system will include modules for input and output processing, the assimilation of data from various sources, and coordination of the model in operational mode. Satellite data will be obtained from the SatBaltyk project (www.satbaltyk.pl), which will be used for assimilation after being processed for this purpose. At its boundaries, the model will use results from a 3D coupled ecosystem model of the Baltic Sea, 3D CEMBS (Dzierzbicka-Głowacka et al. 2013a, 2013b, Nowicki et al. 2015, 2016), and weather forecasts from the UM model created by ICM UW.

The results of the model work will be made available to users of the FindFish Knowledge Transfer Platform, which will be prepared during the fourth stage of the project. The platform will integrate the results of the project, which will be stored in dedicated databases, with ICT systems on fishing vessels to provide current access to forecasts of hydrodynamic and biochemical data and the potential locations of fish species that are targets of commercial fisheries.

The fifth stage will be testing the platform. The results of the commercial catches of a number of vessels will be compared. The effectiveness of fishing cruises executed with and without the system will be compared. The results of the EcoFish model with actual fishing results will also be compared. The results of the tests will help to determine whether the system is a useful source of information for fishers, scientists, and fisheries management and whether its implementation leads to improved performance and higher competitiveness. The final step will be to implement the FindFish platform for operational use. Implementation will cover both the technical aspects of launching the platform by IT staff on the target server and its implementation by fishers on vessels.

In summation, the use of modern measurement techniques and computer modeling will allow us to more accurately determine the locations of certain commercial fish species caught in the southern Baltic Sea region. This will result in more selective fishing and in reduced costs for the fisheries.

From a technical point of view, the implementation of the FindFish Platform will permit numerical predictions of the conditions of the marine environment of the Gulf of Gdansk, hydrodynamic, biochemical, and ecological conditions, and the places of most favorable conditions for fish habitat. This will provide ready access to necessary information on the Gulf of Gdansk environment, which could translate into the reduction of by-catch and the improved selection of fishing areas based on qualitative rather than quantitative reasons, data records, and easy access to and usage of the system from internet browsers.

Taking into account the impact of commercial fisheries on the marine environment, it is assumed that the implementation of the FindFish Platform by fisher associations will provide many positive effects. These will include reduced fish mortality through by-catch reductions, the sustainable development of marine fisheries, the protection of the marine ecosystems of the Gulf of Gdansk and protected areas, and increased fisheries control by the fishers themselves. This will also help reduce the cost of the fisheries and the time fishers spend looking for fish.

The significant impact on the environment and the fisheries will be observed during the five to ten years following the conclusion of the project. However, the first changes should be seen earlier. FindFish could be useful not only for fishers and scientists, but also for manufacturers, importers, consumers, market analysts, policy makers, and fisheries administrators by enabling additional fish protection measures in areas inhabited by juvenile fishes or by-catch fish species that are currently unnecessarily exploited. 
Acknowledgments. Financial support for this study was provided by the project entitled "Knowledge transfer platform FindFISH - Numerical Forecasting System for the Marine Environment of the Gulf of Gdańsk for Fisheries" (no. RPPM.01.01.01-22-0025/16-00) funded by the European Union through the European Regional Development Fund within the Pomorskie Voivodeship Regional Operational Programme for 2014-2020.

Author contributions. L.D.G. conceived of the experiments, developed the general concept of the paper, prepared the figures, wrote the paper, and reviewed the drafts of the paper; A.N. developed the general concept of the paper, wrote the paper, and reviewed the drafts of the paper; M.J. wrote the sections on the EcoFish model and platform testing; B.S. wrote the section on assessing the state of the environment of the Gulf of Gdansk; P.P. wrote the sections on the FindFish platform and testing the platform; P.P. wrote the section on assessing the state of the environment of the Gulf of Gdansk; G.Ł. wrote the sections on fishing expeditions and the operational use of the FindFish platform.

\section{References}

Dzierzbicka-Głowacka L., Jakacki J., Janecki M., Nowicki A. 2013a - Activation of the operational ecohydrodynamic model (3D CEMBS) - the hydrodynamic part Oceanologia 55: 519-541.

Dzierzbicka-Głowacka L., Janecki M., Nowicki A., Jakacki J. $2013 \mathrm{~b}$ - Activation of the operational ecohydrodynamic model (3D CEMBS) - the ecosystem module Oceanologia 55: 543-572.

European Commission 2009 - Wspólna polityka rybołówstwa - Podręcznik użytkownika - Urząd Oficjalnych Publikacji Wspólnot Europejskich, Luksemburg, 36 p. ISBN 978-92-79-09886-4 (in Polish) (ec.europa.eu/fisheries).
Hiddink J.G., Coleby C. 2011 - What is the effect of climate change on marine fish biodiversity in the area of low connectivity, the Baltic Sea? - Glob. Ecol. Biogeogr. 21: 637-646.

MacKenzie B.R., Köster F.W. 2004 - Fish Production and Climate: Sprat in the Baltic Sea - Ecology 85: 784-794.

MacKenzie B.R., Gislason H., Möllmann C., Köster F.W. 2007 - Impact of 21st century climate change on the Baltic Sea fish community and fisheries - Glob. Change Biol. 13: 1348-1367.

Nowicki A., Dzierzbicka-Głowacka L., Janecki M., Kałas M. 2015 - Assimilation of the satellite SST data in the 3D CEMBS model - Oceanologia 57: 17-24.

Nowicki A., Rak D., Janecki M., Dzierzbicka-Glowacka L. 2016 - Accuracy assessment of temperature and salinity computed by the 3D Coupled Ecosystem Model of the Baltic Sea (3D CEMBS) in the Southern Baltic - J. Oper. Oceanogr. 9: 67-73.

Planqué B., Loots C., Petitgas P., Lindstrøm U., Vaz S. 2011 Understanding what controls the spatial distribution of fish populations using a multi-model approach - Fish. Oceanogr. 20: 1-17.

Rushton S.P., Ormerod S.J., Kerby G., 2004 - New paradigm for modelling species distributions? - J. Appl. Ecol. 41: 193-200.

Schnute J., Richards L.J. 2011 - Use and abuse of fishery models - Can. J. Fish. Aquat. Sci. 58: 10-17.

Sindermann C.J. 1980 - Pollution effects on fisheries - potential management activities - Helgoland Mar. Res. 33: 674-686.

Smith M.D., Zhang J., Coleman F. 2007 - Structural Modeling of Marine Reserves with Bayesian Estimation Mar. Resour. Econ. 22: 121-136.

Thøgersen T., Hoff A., Frost H.S. 2015 - Fisheries management responses to climate change in the Baltic Sea - Climate Risk Management 10: 51-62

Walsh S.J., Engås A., Ferro R., Fonteyne R., Van Marlen B. 2002 - To catch or to conserve more fish: the evolution of fishing technology in fisheries science - 100 Years of Science under ICES, ICES Marine Science Symposia 215: 493-503. 